\title{
The association between adherence to the New Nordic Diet and diet quality
}

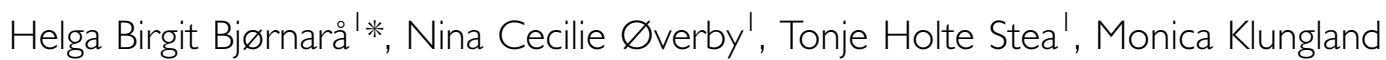 \\ Torstveit', Elisabet Rudjord Hillesund', Lene Frost Andersen², Sveinung Berntsen' and \\ Elling Berel \\ 'Department of Public Health, Sport and Nutrition, Faculty of Health and Sport Sciences, University of Agder, \\ Kristiansand, Norway; ${ }^{2}$ Department of Nutrition, University of Oslo, Oslo, Norway
}

\section{Abstract}

Background: Previous studies have reported a positive association between scoring on healthy Nordic diet scales and the intake of healthy foods and nutrients, and also with higher intake of meat, sweets, cakes, and energy in general. These studies have used the same food frequency questionnaire (FFQ) responses for constructing the diet score as for calculating intakes of foods and nutrients. Thus, it is not clear whether the coexistence of healthy and less healthy dietary aspects among adherers to Nordic diets would occur even though separate methods were applied for exploring these relations.

Objective: To assess the association between adherence to the New Nordic Diet (NND), derived from an FFQ, and diet quality, determined from two 24-h dietary recall interviews.

Design: In total, 65 parents of toddlers in Southern Norway answered the NND FFQ and two 24-h dietary recall interviews. NND adherence was determined from the FFQ and categorized into low, medium, and high adherence. The two 24-h recalls provided data for the intake of specific foods and nutrients, selected on the basis of the Norwegian food-based guidelines as an indicator of a healthy diet. The Kruskal-Wallis test was used for assessing differences in food and nutrient intake across NND groups.

Results: High NND adherence derived from FFQ was associated with a high intake of fruits $(p=0.004)$ and fiber $(p=0.02)$, and a low intake of meat $(p=0.004)$ and margarines $(p=0.05)$, derived from recalls. A larger proportion of high NND adherers $(68 \%)$ complied with the national dietary recommendation targeting meat intake compared with low NND adherers $(29 \%)(p=0.04)$.

Conclusion: The present study showed that higher NND adherence measured with FFQ was associated with a higher intake of selected healthy foods and nutrients, measured with recalls. However, a higher intake of meat, sweets, and energy, as earlier reported, was not observed.

Keywords: New Nordic Diet; diet score; Norwegian food-based guidelines; dietary intake; nutrient intake

Responsible Editor: Per Ole Iversen, University of Oslo, Norway.

Received: 16 January 2016; Revised: 19 April 2016; Accepted: 10 May 2016; Published: I June 2016

\section{A} $\mathrm{s}$ a result of the demonstrated protective effects of the Mediterranean diet on disease (1-3) and mortality (2), the possible protective effects of other regional diets have gained attention. In the Nordic countries, dietary scores have been constructed in order to explore adherence to different aspects of the Nordic diets with expected health-promoting effects (4-6). Recently, observational studies have reported that compliance with Nordic diets is associated with lower mortality $(4,7)$ and a reduced risk of non-communicable diseases $(5,8-13)$. However, the evidence is not quite consistent, as other studies have failed to demonstrate associations between Nordic diets and breast cancer (14), colorectal cancer
(15), or type 2 diabetes (16) and have reported equivocal associations with cardio-metabolic risk factors (17).

Three studies have examined dietary composition and nutrient intake related to three different Nordic diet scores, concluding that high scores were associated with an increased intake of healthy foods $(5,18)$ and essential nutrients $(5,6,18)$. In a sample of Swedish women (18), higher scores on the Healthy Nordic Food Index (HNFI) were associated with a higher intake of the six food groups included in the score, that is, apples/pears, cabbage, root vegetables, whole grain bread, oatmeal, and fish/shellfish, in addition to fiber and higher micronutrient density. Likewise, participants in the Norwegian Mother and 
Child Cohort Study (MoBa), who attained higher ratings in the New Nordic Diet (NND) score, reported a higher consumption of healthy foods like whole grains, fish, fruits, and vegetables, and thus increased fiber intake and overall higher nutrient density (5). In a representative sample of the Finnish population, increased compliance with the Baltic Sea Diet Score implied a higher intake of fiber, iron, vitamin $\mathrm{D}$, and folate, and a decreased intake of saturated fatty acids (SFAs) and alcohol (6). Moreover, high diet scores were associated with being more physically active $(6,18)$ and more likely to exercise (5).

Nevertheless, not all reported associations between diet scores and food intake have been in a healthier direction. In Norway, 'high' NND adherers were reported eating slightly more meat, cakes, and desserts than 'low' NND adherers (5), while Swedish women with high scores on the HNFI also reported a higher intake of less healthy foods such as processed meat and sweets (18). Moreover, in the Finnish sample higher intake of sodium and lower intake of polyunsaturated fatty acids (PUFAs) was observed among adherers to the Baltic Sea Diet Score (6). In all three studies, a high score was positively associated with energy intake $(5,6,18)$.

These three studies, examining the association between adhering to Nordic diets and food/nutrient intake, all used the same food frequency questionnaire (FFQ) for constructing the diet score as for calculating intakes of foods and nutrients. Therefore, based on the previously reported coexistence of healthy and less healthy dietary aspects among adherers to predefined healthy Nordic diets, the aim of the current study was to assess the association between adherence to the NND score, derived from an FFQ, and diet quality, determined from two 24-h dietary recall interviews.

\section{Methods}

\section{Design and study sample}

The present data originate from the project Healthy and Sustainable Lifestyle, which in 2014 collected data in collaboration with the Child Food Courage project (19). As part of these projects, a web-based questionnaire was constructed to explore lifestyle behaviors, self-perceived health and quality of life, as well as basic demographic and socioeconomic variables (e.g. sex, age, height, weight, ethnicity, and educational attainment) among parents of toddlers. For the current methodological study, a convenience sample, consisting of parents of toddlers born between 2008 and 2011, was recruited through kindergartens. The leader of each kindergarten was asked to distribute the study invitation to eligible parents who were able to speak and read Norwegian. For each child, either the mother or the father could participate. Parents were informed about the purpose and implications of the study through a web page and via e-mail distribution.
In total, 1,191 parents from 19 kindergartens in the county of Vest-Agder, Southern Norway, were invited to participate. A total of 86 (7\%) parents signed up. Parents provided consent electronically, followed by administration of the questionnaire survey by e-mail. Subsequently, two 24-h dietary recalls were conducted by telephone 2-4 weeks apart, level of physical activity was recorded objectively for seven consecutive days, and anthropometric measurements were undertaken (height and body mass). Data collection was conducted between March and August 2014. In total, 56 parents ( $65 \%$ of those who signed up) completed all measurements, that is, the electronic questionnaire, two dietary recalls, and the physical activity assessment, while 65 parents $(76 \%)$ completed the questionnaire and two dietary recalls, and 75 parents $(87 \%)$ completed the questionnaire only.

\section{Measures}

\section{The New Nordic Diet score}

The electronic questionnaire incorporated an FFQ assessing participants' habitual frequency of intake of selected foods, without specification of amounts consumed. The foods assessed included foods that are part of the concept of a NND, which has been suggested due to its inherent properties that potentially promote health, environmental sustainability, and food traditions (20), without compromising palatability (21). The NND consists of healthy foods native to the Nordic climate or foods that can be produced or cultivated in the Nordic climate, like certain fruits, berries, root vegetables, cabbages, whole grains, wild fish and game, potatoes, and rapeseed oil $(20,22)$. The NND score was previously developed to capture adherence to the NND in observational studies (5), and has recently shown acceptable test-retest reliability (23). The NND score comprises 10 subscales selected to summarize meal pattern and habitual intake of typical Nordic foods. Appendix 1 describes the components underlying the construction of the 10 subscales in the present study, including questionnaire items and frequency options. In the present study, the number of items forming the basis for each subscale ranged from 1 to 5 , a total of 24 questions. Each subscale was dichotomized by the sex-specific median and assigned values of ' 0 ' or ' 1 ', with ' 1 ' indicating a more frequent consumption of main meals (subscale 1) or a more favorable intake of selected foods (subscale 2-10). Each subscale was assigned equal weightage, and adding the subscales yielded a score ranging from 0 to 10 , with increasing scores indicating higher compliance with the NND. The total score was trichotomized grouping participants into 'low' (0-3 points), 'medium' ( $4-5$ points), and 'high' ( $6-10$ points) adherence to the NND (5), with cutoffs for groupings determined to obtain the most equally sized groups. 


\section{4-Hour dietary recall interviews}

Two unannounced 24-h dietary recalls were collected by telephone, 2-4 weeks apart by two trained interviewers, after completion of the FFQ. Each interview lasted for approximately 20-30 min, aiming to obtain detailed information on all foods and beverages consumed by the participants in the period between waking up on the preceding day and waking up on the interview day. A booklet containing photographs of various portion sizes for common foods and standard sizes of glasses, cups, and plates (24) was available on the project's web page to ease the estimation of portion sizes from memory. Dietary intake was reported for one weekday and one weekend day by 21 participants $(32 \%)$, of whom 18 participants $(86 \%)$ reported for a Sunday, while 3 participants $(14 \%)$ reported for a Saturday. The remaining 44 participants $(68 \%)$ reported dietary intake for two weekdays, due to feasibility. Dietary information was converted into daily energy and nutrient intakes using the food calculation software KBS V 7.0, linked directly to the food composition database N3. The Norwegian food composition table from 2006 (25) forms the basis for this food composition database, which is also supplemented with additional food items from reliable sources. The 24-h recall functionality of the KBS program was developed specifically for the Norkost 3 study, which represents the latest national dietary survey conducted among a representative sample of Norwegian adults (24). Nutritional supplements were excluded from the calculations, as food intake per se was that of interest in this study, and what corresponds with the concept NND.

In order to assess diet quality across NND adherence, specific foods and nutrients assessed by the two 24-h dietary recalls were selected, based on the official Norwegian food-based guidelines (26) as an indicator of a healthy diet. Foods assessed were 'Vegetables (fresh and frozen)', 'Fruits and berries (fresh)', 'Fruit juice', 'Whole grain products', 'Refined grain products', 'Fish', 'Meat', 'Low fat dairy products', 'Fatty dairy products', 'Vegetable oils', 'Margarines', 'Butter', 'Chocolate, candies and sugar-sweetened beverages', and 'Water'. Selected nutrients were fiber, added sugar, and sodium. In addition, we assessed energy intake across NND groups. Also, the proportion from each NND adherence category meeting the following quantitative Norwegian food recommendations was calculated; 'Eat at least five portions of vegetables, fruits, and berries every day', 'Eat whole grains every day', 'Eat fish for dinner two to three times a week and preferably also as sandwich spread', 'Choose lean meat and lean meat products. Limit the amount of processed meat and red meat', 'Choose foods containing little salt, and limit the use of salt for cooking', and 'Avoid sugar rich foods and beverages for everyday use'. Calculations were performed in line with the methodology of the Norkost 3 study (24), entailing that for whole meal bread,
$40 \%$ of the product weight was accounted for as whole grains, while for muesli/mixed cereals, $50 \%$ of the product weight was included. Further, cut-offs for compliance were set at $70 \mathrm{~g}$ whole grain/day for women and $90 \mathrm{~g} /$ day for men. Recommendations regarding fish intake and meat consumption were operationalized into daily intake, as recommended weekly amounts are 300-450 g of fish (ready to eat), and $<500 \mathrm{~g}$ of red and processed meat (ready to eat), for both females and males. Consequently, due to the features of the food calculation software used (KBS V 7.0), 40\% of the product weight of processed fish products was included (24), and for meat intake the recommended commodity weight (750 g/week) (27) represented the cut-off.

Moreover, the habitual frequency of consumption of selected foods (i.e. vegetables, fruits and berries, fruit juice, whole grain products, refined grain products, fish, meat, and sweet pastries, candies, and sugar-sweetened beverages) across NND adherence groups was assessed using FFQ data. Although amounts were not specified, frequencies would allow for an examination of tendencies across groups, using the same FFQ data for determining NND adherence as for assessing dietary intake, in line with the methodology applied in the earlier studies $(5,6,18)$.

\section{Physical activity and anthropometric measurements}

To enable exploration of the physical activity level in the present sample, as one relevant sample characteristic, and also the relation between energy intake and energy expenditure, the monitor SenseWear Armband Mini (SWA; BodyMedia, Pittsburgh, Pennsylvania, USA) was used. SWA includes a 3-axis accelerometer, a heatflux sensor, a skin temperature sensor, and a near-body ambient temperature sensor (28). Data from these sensors were combined with sex, age, body weight, and height to estimate physical activity intensity and energy expenditure using algorithms developed by the manufacturer. Participants were instructed to wear the monitor on the upper left arm (on the triceps, at mid humerus point) for seven consecutive days, only removing it for bathing, or any other water activity. Those with a nickel allergy were discouraged from participating $(n=5)$, as wearing the monitor may cause skin rashes due to $8 \%$ nickel content. Data were downloaded using SenseWear Professional V.8.1 (BodyMedia, Pittsburgh, Pennsylvania, USA). A valid day was defined as at least $80 \%(19.2 \mathrm{~h}$ ) wearing time, and a minimum of four valid days with at least one weekend day was required for participants to be included in the analyses $(29,30)$. Data were calculated and reported as mean values per day. Participants exceeding 21.5 $\mathrm{min} /$ day with moderate and vigorous physical activity, in bouts of at least $10 \mathrm{~min}$ duration, were classified as meeting the recommendations for physical activity (26, $31)$. The cut-off defining moderate to vigorous intensity was 3 metabolic equivalents (METs) (32). Anthropometric 
measurements were obtained by trained staff, with subjects barefoot and dressed in light clothes. Height was measured using a portable stadiometer with the head in the Frankfort plane, two measurements were taken and added with a third if the first two differed by $>1 \%$. The mean of the closest two measurements was calculated. Body mass was measured by a segmental multi-frequency bioelectrical impedance analysis (BIA), conducted with In Body 720 (Biospace Co., Ltd., Seoul, Korea). Body mass index (BMI) was computed, as this represents one significant and commonly included sample characteristic, and participants with a BMI $\geq 25 \mathrm{~kg} / \mathrm{m}^{2}$ were categorized as overweight/obese (33). In compliance with the measurement protocol, participants were instructed to abstain from exercise and food within $2 \mathrm{~h}$ of testing, and immediately prior to the measurement to avoid showering and sauna, and to empty their bladder. Pregnant women were excluded from the body composition measurements $(n=1)$.

\section{Statistical analysis}

Statistical analyses were performed with the statistical software package IBM SPSS Statistics version 22.0 (IBM Corp., Somers, New York, USA). To explore differences in sample characteristics across NND adherence categories, Chi-square test for independence $\left(\chi^{2}\right)$ was used. Food consumption variables were skewed, thus the Kruskal-Wallis test was applied for assessing differences in food, nutrient and energy intakes, and energy expenditure, across NND categories. Results are presented as median and quartiles. Differences in compliance with the Norwegian quantitative food-based dietary guidelines according to NND adherence group was assessed with Chi-square. A two-sided $p$-value of $<0.05$ was considered statistically significant.

\section{Results}

A total of 65 participants were included in the final analyses. Mean age in the study sample was 35.2 years (SD \pm 5.0 years), 55 participants $(85 \%)$ were females, 58 participants $(89 \%)$ were native Norwegians, and 37 participants $(57 \%)$ reported four or more years of university or college education (Table 1). Furthermore, 13 participants $(20 \%)$ were overweight or obese, while 46 participants $(82 \%)$ met the national recommendations on physical activity (26). No significant differences were observed in sample characteristics across NND categories (Table 1). Participants were categorized according to the NND score into low $(n=17)$, medium $(n=23)$, or high $(n=25)$ NND adherence, representing 26, 35, and 39\% of the sample, respectively. Among the 21 participants $(32 \%)$ reporting dietary intake for one weekday and one weekend day, distribution across NND adherence groups was: low $(n=5)$, medium $(n=6)$, and high $(n=10)$, representing 24,28 , and $48 \%$, respectively.
Table 1. Selected characteristics of the study sample in total $(n=65)$, according to NND adherence

\begin{tabular}{|c|c|c|c|c|c|}
\hline & \multicolumn{4}{|c|}{ Degree of NND adherence } & \multirow[b]{3}{*}{$P^{*}$} \\
\hline & $\begin{array}{l}\text { Whole } \\
\text { sample } \\
(n=65)\end{array}$ & $\begin{array}{c}\text { Low } \\
(n=17)\end{array}$ & $\begin{array}{l}\text { Medium } \\
(n=23)\end{array}$ & $\begin{array}{c}\text { High } \\
(n=25)\end{array}$ & \\
\hline & $n(\%)$ & $n(\%)$ & $n(\%)$ & $n(\%)$ & \\
\hline \multicolumn{6}{|l|}{ Sex } \\
\hline Female & $55(85)$ & $14(82)$ & $20(87)$ & $21(84)$ & 0.92 \\
\hline \multicolumn{6}{|l|}{ Age (yrs) } \\
\hline $20-34$ & $31(48)$ & $8(47)$ & $12(52)$ & II (44) & \\
\hline$\geq 35-47$ & $34(52)$ & $9(53)$ & II (48) & $14(56)$ & 0.85 \\
\hline \multicolumn{6}{|l|}{ Ethnicity } \\
\hline Native Norwegian ${ }^{\dagger}$ & $58(89)$ & $16(94)$ & $21(91)$ & $21(84)$ & 0.54 \\
\hline \multicolumn{6}{|l|}{ Educational attainment } \\
\hline Higher education & $37(57)$ & $13(77)$ & $9(39)$ & $15(60)$ & 0.06 \\
\hline \multicolumn{6}{|l|}{ Weight status } \\
\hline Overweight/obese ${ }^{\S}$ & $13(20)$ & $4(24)$ & $5(22)$ & $4(16)$ & 0.81 \\
\hline \multicolumn{6}{|l|}{ Physical activity level } \\
\hline Physically active\| & $46 \uparrow(82)$ & II (73) & $16(80)$ & $19(91)$ & 0.40 \\
\hline
\end{tabular}

NND, New Nordic Diet. * $p$-values calculated from Chi-square test for independence $\left(\chi^{2}\right)$. 'Both parents born in Norway. ${ }^{\dagger} \geq 4$ years of university or college education. ${ }^{\S}$ Body mass index $\geq 25 \mathrm{~kg} / \mathrm{m}^{2}$. $\|>21.5$ $\mathrm{min} /$ day with moderate and vigorous physical activity, in bouts of at least $10 \mathrm{~min}$ duration, measured by the activity monitor SenseWear Armband Mini. -For physical activity level $n=56 ; 15,20$, and 2 I parents categorized into low, medium, and high NND, respectively.

Different consumption of selected foods (Table 2) across NND groups was detected for meat $(p=0.004)$, fruits and berries $(p=0.004)$, and margarines $(p=0.05)$, entailing that those classified as 'low' NND adherers reported the highest consumption of meat and margarines, while 'high' NND adherers reported the largest intake of fruits and berries. For the other foods assessed, that is, fresh and frozen vegetables, fruit juice, whole grain products, refined grain products, fish, low-fat dairy products, fatty dairy products, vegetable oils, butter, chocolate, candies and sugar-sweetened beverages, and water, no significant differences were observed. The relative intake of dietary fiber $(\mathrm{E} \%)$ differed significantly across NND groups; fiber contributed with $2.7 \mathrm{E} \%$, $2.4 \mathrm{E} \%$, and $2.1 \mathrm{E} \%(p=0.02)$, in 'high', 'medium', and 'low' NND adherers, respectively. For added sugar and sodium, no differences according to NND classifications were found. Likewise, energy intake and energy expenditure did not differ across NND groups (Table 2).

Regarding the frequency of habitual food intake (results not shown) measured with FFQ, significant differences across NND adherence groups were found for all foods except from fruit juice. 'High' NND reported to eat vegetables, fruits and berries, whole grain products, 
Table 2. Daily energy expenditure, energy intake, and consumption of fiber, added sugar, sodium (Na), and selected foods, according to NND adherence

\begin{tabular}{|c|c|c|c|c|c|c|c|}
\hline & \multicolumn{6}{|c|}{ Degree of NND adherence } & \multirow[b]{3}{*}{$p^{*}$} \\
\hline & \multicolumn{2}{|c|}{ Low $(n=17)$} & \multicolumn{2}{|c|}{ Medium $(n=23)$} & \multicolumn{2}{|c|}{ High $(n=25)$} & \\
\hline & Median $^{\dagger}$ & (QI, Q3) & Median & (QI, Q3) & Median & (QI, Q3) & \\
\hline Energy expenditure $(\mathrm{kJ})^{*}$ & 11,026 & $(10,041,12,203)$ & $|0,62|$ & $(10,040,11,870)$ & 11,456 & $(10,074,12,436)$ & 0.65 \\
\hline Energy intake $(\mathrm{kJ})$ & 9,361 & $(7,762,12,200)$ & 8,308 & $(7,4 \mid 8,10,992)$ & 8,883 & $(7,225,10,961)$ & 0.46 \\
\hline Fiber $(g)$ & 24.5 & $(21.8,27.7)$ & 26.4 & $(22.0,32.0)$ & 30.2 & $(23.0,40.3)$ & 0.07 \\
\hline Fiber (E\%) & 2.1 & $(1.6,2.6)$ & 2.4 & $(2.1,2.7)$ & 2.7 & $(2.2,3.1)$ & 0.02 \\
\hline Added sugar (g) & 38.1 & $(17.8,60.4)$ & 27.8 & $(10.7,40.4)$ & 21.1 & $(12.7,36.2)$ & 0.19 \\
\hline Added sugar (E\%) & 6.9 & $(3.4,8.8)$ & 4.7 & $(2.5,7.5)$ & 4.4 & $(2.7,6.7)$ & 0.17 \\
\hline $\mathrm{Na}(\mathrm{mg})$ & 2738.0 & $(2214.5,3795.0)$ & 2786.0 & $(1828.0,3860.0)$ & 2789.0 & $(1984.5,3778.5)$ & 0.92 \\
\hline Vegetables (fresh and frozen) & 139.9 & $(86.8,218.6)$ & 140.6 & $(76.0,198.5)$ & 164.4 & $(110.6,243.5)$ & 0.56 \\
\hline Fruits and berries (fresh) & 102.5 & $(60.8,207.8)$ & 150.0 & $(120.5,305.0)$ & 267.5 & $(187.6,348.8)$ & 0.004 \\
\hline Fruit juice & 93.8 & $(0.0,3 \mid 2.5)$ & 0.0 & $(0.0,187.5)$ & 0.0 & $(0.0,122.5)$ & 0.15 \\
\hline Whole grain products & 57.7 & $(33.6,110.0)$ & 53.7 & $(30.1,117.6)$ & 67.2 & $(34.0,136.0)$ & 0.60 \\
\hline Refined grain products & 130.2 & $(52.7,169.7)$ & 86.2 & $(51.3,166.0)$ & 74.9 & $(38.7,162.7)$ & 0.67 \\
\hline Fish\| & 21.3 & $(0.0,60.1)$ & 5.0 & $(0.0,85.3)$ & 38.5 & $(0.0,86.8)$ & 0.53 \\
\hline Meat & 167.4 & $(134.6,233.8)$ & 116.5 & $(54.2,189.6)$ & 102.0 & $(60.8,128.8)$ & 0.004 \\
\hline Low fat dairy products & 110.0 & $(12.0,283.15)$ & 142.5 & $(62.5,320.3)$ & 125.0 & $(49.8,406.3)$ & 0.60 \\
\hline Fatty dairy products & 146.0 & $(71.7,187.3)$ & 75.2 & $(40.0,154.9)$ & 88.0 & $(57.0,155.4)$ & 0.20 \\
\hline Vegetable oils & I.I & $(0.0,5.1)$ & 0.0 & $(0.0,3.0)$ & 0.3 & $(0.0,2.3)$ & 0.63 \\
\hline Margarines & 7.5 & $(0.7,19.6)$ & 5.5 & $(2.5,11.6)$ & 1.1 & $(0.0,7.9)$ & 0.05 \\
\hline Butter & 5.6 & $(3.2,12.1)$ & 5.0 & $(1.6,10.2)$ & 6.8 & $(2.2,16.7)$ & 0.50 \\
\hline $\begin{array}{l}\text { Chocolate, candies, and } \\
\text { sugar-sweetened beverages }\end{array}$ & 42.0 & $(6.3,205.0)$ & 24.5 & $(1.0,163.1)$ & 4.0 & $(0.0,64.5)$ & 0.15 \\
\hline Water & 1000.0 & $(601.9,1297.0)$ & 1215.0 & $(8|2.5| 893.8)$, & 1120.0 & $(795.0,1452.5)$ & 0.33 \\
\hline
\end{tabular}

NND, New Nordic Diet. *Kruskal-Wallis test was used to derive $p$-values. ${ }^{\dagger}$ Median and quartiles were calculated from two $24-h$ dietary recalls. ${ }^{\dagger}$ For energy expenditure (measured by the activity monitor SenseWear Armband Mini) and energy intake (assessed by two 24-h dietary recalls). $n=56$; I5, 20, and 21 parents categorized into low, medium, and high NND, respectively. ||lncludes lean fish, fatty fish, fish products, and selected fish toppings. -Includes poultry, pork, beef, game (all unprocessed), ground meat, and processed meat (salted meat, minced meat, sandwich meat, and liver paste).

and fish more frequently than 'low' NND, while 'low' NND recorded more frequent consumption of refined grain products, meat, and sweet pastries, candies, and sugar-sweetened beverages than 'high' NND.

Table 3 shows that a greater proportion of 'high' NND adherers complied with the guideline to 'Choose lean meat and lean meat products and limit the amount of processed meat and read meat', than 'low' NND adherers $(68 \%$ versus $29 \%, p=0.04)$. For the remaining five recommendations of interest, no significant differences between NND adherence groups were found.

\section{Discussion}

In the present study, the association between adherence to the NND, derived from an FFQ, and diet quality, determined from two 24-h dietary recall interviews, was assessed. In line with former findings, the trend was that 'high' NND adherers reported a more favorable diet in general $(5,6,18)$, and a higher intake of fruits $(5,18)$ and dietary fiber $(5,6,18)$. Contrasting previous findings
$(5,18)$, neither higher intake of meat or sweets, nor higher energy intake or higher physical activity levels was observed among 'high' NND adherers $(5,6,18)$.

The previously observed coexistence of healthy and less healthy dietary elements among adherers to predefined healthy Nordic diets could have different explanations. First, it may be real, that is, that those who achieve high scoring on the Nordic scales have higher intakes of a wide variety of foods, which may be characterized as both healthy and less healthy. High intake of healthy foods and beverages will most likely have positive health effects, in spite of unhealthy elements in the diet. This aspect may partly explain previous results, especially as higher scoring on the Nordic scales was associated with being more physically active, or more likely to exercise, as well. Dietary factors not included when constructing a specific diet score could confound true associations between the healthier aspects of the diet and relevant outcomes. An example is meat, which has been reported to associate positively with colorectal cancer (34), and also with 
Table 3. Proportions meeting the quantitative recommendations incorporated in the official Norwegian food-based dietary guidelines, according to NND adherence

\begin{tabular}{|c|c|c|c|c|c|}
\hline \multirow[b]{3}{*}{ Quantitative dietary recommendations } & \multirow[b]{3}{*}{$\begin{array}{c}\text { Behavior required } \\
\text { for scoring }\end{array}$} & \multicolumn{3}{|c|}{ Degree of NND adherence } & \multirow[b]{3}{*}{$p^{*}$} \\
\hline & & Low $(n=17)$ & Medium $(n=23)$ & High $(n=25)$ & \\
\hline & & $\begin{array}{l}\text { \% adhering to } \\
\text { recommendation }\end{array}$ & $\begin{array}{l}\% \text { adhering to } \\
\text { recommendation }\end{array}$ & $\begin{array}{l}\% \text { adhering to } \\
\text { recommendation }\end{array}$ & \\
\hline $\begin{array}{l}\text { 3: 'Eat at least five portions of vegetables, fruits, and berries } \\
\text { every day }{ }^{\dagger}\end{array}$ & $>500 \mathrm{~g} /$ day & 29 & 35 & 48 & 0.43 \\
\hline 4: 'Eat whole grains every day' & $\begin{array}{l}>70 \mathrm{~g} / \text { day (women) } \\
>90 \mathrm{~g} / \text { day (men) }\end{array}$ & 35 & 35 & 40 & 0.92 \\
\hline $\begin{array}{l}\text { 5: 'Eat fish for dinner two to three times a week and } \\
\text { preferably also as toppings" }\end{array}$ & $>43 \mathrm{~g} /$ day & 29 & 39 & 48 & 0.48 \\
\hline $\begin{array}{l}\text { 6: "Choose lean meat and lean meat products. Limit the } \\
\text { amount of processed meat and read meat" }\end{array}$ & $<107$ g/day & 29 & 61 & 68 & 0.04 \\
\hline $\begin{array}{l}\text { 9: 'Choose foods containing little salt, and limit the use of } \\
\text { salt for cooking'. }\end{array}$ & $<6$ g salt $(\mathrm{NaCl})$ per day & 24 & 39 & 36 & 0.56 \\
\hline 10: 'Avoid sugar rich foods and beverages for everyday use'. & $<10 \mathrm{E} \%$ sugar/day & 88 & 87 & 96 & 0.51 \\
\hline
\end{tabular}

NND, New Nordic Diet. *Proportions were calculated using chi-square. 'ंFor those with an average intake of at least $100 \mathrm{~g}$ of fruit juice, $100 \mathrm{~g}$ of juice were included. "Includes lean fish, fatty fish, fish products, and selected fish toppings. ${ }^{\S}$ Includes lean, red meat (unprocessed), ground meat, and processed meat (salted meat, minced meat, sandwich meat, and liver paste).

compliance to the HNFI (18). These relations may partly explain the lack of an inverse association between greater scoring on the HNFI, and colorectal cancer (15). Second, the scales assessing adherence to the different Nordic diets might be biased as a result of the consistency motif (35), that is, participants falling into a pattern of similar responses when answering comparable questions, which is a tendency that could apply to FFQs. Those reporting to eat more of the healthy Nordic foods might also erroneously report eating more of certain less healthy foods. If so, it may be debatable whether the dietary scores actually capture what they intend to capture. Third, artificial covariance (35) could have biased the earlier reported associations, due to using the same questionnaire responses for deriving the dietary score and for calculating food and nutrient intakes. In turn, such false associations could result in invalid inferences regarding diet-health relations. Since measurement errors would be less correlated if applying separate methods for these two operations (36), it may be favorable to construct the diet score from an FFQ, while using dietary recalls for estimating intake of foods and nutrients.

The FFQ was unfortunately not tested for validity, and misreporting, especially the underreporting of foods generally considered unhealthy, is a common challenge when data are self-reported $(36,37)$. However, if randomly distributed, misreporting should still allow the ranking of participants into groups according to intake. Besides, although the underlying concept of interest was NND adherence at the group level, the limited sample size in this study ideally calls for more than two $24-\mathrm{h}$ recall interviews to reduce the influence of day-to-day variations in food consumption. This uncertainty seems to be reflected through the lack of a consistent trend in the results, and especially foods eaten more seldom, like fish, are the most sensitive for day-to-day variations. Moreover, all groups reported considerably lower energy intake than the objectively measured energy expenditure. Possible explanations might be increased activity levels caused by awareness of being observed (38), low energy intake as a result of the misreporting or underreporting of food consumption, or poor repeatability (37), due to the wide variations in food intake from one day to another.

On the other hand, our findings concerning the frequency of habitual food consumption, determined from the FFQ, revealed the same trend as when using separate methods. Hence, although frequencies are not the same as amounts, different observations in the current study compared with the earlier studies on Nordic scales might be related to sample characteristics. A homogenous and selective sample in the present study, in addition to recently collected data, could possibly imply a sample following a healthier diet than parents of toddlers in general, and therefore reduced generalizability. And, since dietary patterns are likely to change over time, the Nordic scales may capture other dietary aspects today, than when exploring data collected 10-20 years ago. In other words, the present results might indicate that the NND score, and similar Nordic scores, capture healthy diets to a larger degree when applied in more contemporary samples.

The results of the current study should be interpreted in the context of several limitations. As mentioned above, 
the study sample was selective and homogenous, that is, the majority being females, native Norwegians, and highly educated, probably caused by a very low response rate $(7 \%)$. Together with a small sample size, these characteristics restricted study power, eligible statistical analyses (e.g. sub-group analyses), and generalizability to the population in general. A notably larger amount of the present sample complied with the recommended physical activity level (26), and fewer were overweight or obese, compared with a representative sample of the Norwegian adult population (39), that is, $82 \%$ versus $32 \%$, and $20 \%$ versus $48 \%$, respectively. Participating parents might have been more health-conscious and more likely to adhere to a favorable lifestyle, including a healthier diet. Unlike the former studies exploring the HNFI (18), the NND (5), and the Baltic Sea Diet Score (6), differences across NND adherence categories were not detected concerning age, educational level, BMI, physical activity level, or energy intake, expressing the homogeneity of the sample. Yet, lack of differences could also be a result of the limited sample size.

Regarding dietary scores as a method for quantifying adherence to dietary patterns, subjectivity is introduced related to the selection and scoring of included components, cut-off points, and so on $(40,41)$. Importantly, although reflecting a larger part of the overall diet, diet scores do not cover all aspects of diet, meaning that other food items not incorporated into the scale could bias the associations under investigation. Also, as cut-offs for the NND score were determined by the median, dietary behavior required for scoring is sample specific, and caution must be exercised when generalizing the results. In light of the sample characteristics, it is plausible that the diet underlying 'low', 'medium', or 'high' NND adherence entailed higher diet quality in the present sample compared to a more representative sample. Still, this procedure for determining cut-offs is in line with the methods applied in previous studies exploring relations between predefined dietary patterns and various health parameters $(4-6,42)$.

In addition to the use of separate methods for determining NND adherence and calculating intakes of foods and nutrients, it may be a study strength that the questionnaire was recently developed, and thus provided contemporary data. Previous studies derived dietary scores from data collected between years 1991 and 1999 (18), 2002 and 2008 (5), and in 2007 (6), implying that dietary patterns might have changed. On the other hand, it could be a disadvantage if NND adherers in the current study were familiar with the proposed favorable characteristics of the foods included in the NND, and gave the anticipated most desirable answers to the questions. Moreover, repeated 24-h recall interviewing is considered one appropriate method for collecting representative dietary data at group level, entailing less participant burden than dietary records (36, 43).
Unequal methodological approaches, or a selective and more recent sample, might partly explain discrepancies in the present findings as compared with earlier studies $(5,6$, 18 ), that is, the previously observed associations between adherence to healthy Nordic diets and the intake of less healthy foods not part of the diets under investigation $(21,22)$. Nevertheless, considering the limitations of the current study, these associations should be further explored in larger and more heterogeneous samples in order to draw conclusions. Also, when applied in epidemiological studies, potential confounding lifestyle and dietary factors not included in the dietary score should be accounted for, since residual confounding could distort explored associations. Increased knowledge concerning potential methodological bias, as discussed in the present study, would be of importance, due to the fact that such bias may result in false inferences regarding diet-disease relations.

\section{Conclusions}

The present study assessed the association between adherence to the NND measured with FFQ and diet quality measured with two 24-h dietary recall interviews, and showed that higher NND adherence was associated with a higher intake of selected healthy foods and nutrients. However, a higher intake of meat, sweets, and energy in general, as earlier reported in adherers to predefined healthy Nordic diets, was not observed, whether assessed by FFQ or 24-h dietary recall. Nonetheless, the methodological limitations in the current study imply replications in larger and more representative samples before inferences can be drawn regarding explanations for these partly differing results.

\section{Authors' contributions}

EB, MKT, NCØ, THS and HBB designed the present study; ERH, EB, and NCØ constructed the initial NND score; HBB, EB, MKT, NCØ, and LFA developed the HSL-questionnaire; HBB and EB prepared the dataset, SBS directed the physical activity assessments; HBB analyzed the data and wrote the paper; HBB and EB had primary responsibility for final content. All authors read and approved the final manuscript.

\section{Disclosure}

This study was conducted according to the guidelines laid down in the Declaration of Helsinki, and research clearance was obtained from The Norwegian Social Science Data Services. Written informed consent was obtained from all subjects.

\section{Acknowledgements}

The authors are grateful to participating parents for their indispensable contribution. 


\section{Conflict of interest and funding}

The authors declare that they have no conflict of interest. This study was funded by the University of Agder.

\section{References}

1. Martinez-Gonzalez MA, Bes-Rastrollo M. Dietary patterns, Mediterranean diet, and cardiovascular disease. Curr Opin Lipidol 2014; 25: 20-6.

2. Sofi F, Cesari F, Abbate R, Gensini GF, Casini A. Adherence to Mediterranean diet and health status: meta-analysis. $\mathrm{Br}$ Med $\mathrm{J}$ 2008; 337a: 1344.

3. Gotsis E, Anagnostis P, Mariolis A, Vlachou A, Katsiki N, Karagiannis A. Health benefits of the Mediterranean diet: an update of research over the last 5 years. Angiology 2015; 66: 304-18.

4. Olsen A, Egeberg R, Halkjær J, Christensen J, Overvad K, Tjønneland A. Healthy aspects of the Nordic diet are related to lower total mortality. J Nutr 2011; 141: 639-44.

5. Hillesund ER, Bere E, Haugen M, Overby NC. Development of a New Nordic Diet score and its association with gestational weight gain and fetal growth - a study performed in the Norwegian Mother and Child Cohort Study (MoBa). Public Health Nutr 2014; 17: 1909-18.

6. Kanerva N, Kaartinen NE, Schwab U, Lahti-Koski M, Männistö S. The Baltic Sea Diet Score: a tool for assessing healthy eating in Nordic countries. Public Health Nutr 2014; 17 : 1697-705.

7. Roswall N, Sandin S, Lof M, Skeie G, Olsen A, Adami HO, et al. Adherence to the healthy Nordic food index and total and cause-specific mortality among Swedish women. Eur $\mathbf{J}$ Epidemiol 2015; 30(6): 509-17. doi: http://dx.doi.org/10.1007/ s10654-015-0021-x

8. Kyrø C, Skeie G, Loft S, Overvad K, Christensen J, Tjønneland A, et al. Adherence to a healthy Nordic food index is associated with a lower incidence of colorectal cancer in women: the Diet, Cancer and Health Cohort Study. Br J Nutr 2013; 109: 920-7.

9. Kanerva N, Kaartinen NE, Schwab U, Lahti-Koski M, Männistö S. Adherence to the Baltic Sea diet consumed in the Nordic countries is associated with lower abdominal obesity. Br J Nutr 2013; 109: 520-8.

10. Kanerva N, Kaartinen NE, Ovaskainen M-L, Konttinen H, Kontto J, Männistö S. A diet following Finnish nutrition recommendations does not contribute to the current epidemic of obesity. Public Health Nutr 2013; 16(5): 786-94.

11. Kanerva N, Loo BM, Eriksson JG, Leiviskä J, Kaartinen NE, Jula A, et al. Associations of the Baltic Sea diet with obesityrelated markers of inflammation. Ann Med 2014; 46: 90-6.

12. Hillesund ER, Overby NC, Engel SM, Klungsoyr K, Harmon QE, Haugen $\mathrm{M}$, et al. Associations of adherence to the New Nordic Diet with risk of preeclampsia and preterm delivery in the Norwegian Mother and Child Cohort Study (MoBa). Eur J Epidemiol 2014; 29: 753-65.

13. Lacoppidan SA, Kyrø C, Loft S, Helnæs A, Christensen J, Hansen CP, et al. Adherence to a healthy Nordic food index is associated with a lower risk of type-2 diabetes - the Danish Diet, Cancer and Health Cohort Study. Nutrients 2015; 7: 8633-44.

14. Li Y, Roswall N, Sandin S, Strom P, Adami HO, Weiderpass E. Adherence to a healthy Nordic food index and breast cancer risk: results from a Swedish Cohort Study. Cancer Causes Control 2015; 26(6): 893-902. doi: http://dx.doi.org/10.1007/ s10552-015-0564-x
15. Roswall N, Li Y, Kyro C, Sandin S, Lof M, Adami HO, et al. No association between adherence to a healthy Nordic food index and colorectal cancer: results from a Swedish Cohort Study. Cancer Epidemiol Biomarkers Prev 2015; 24(4): 755-7. doi: http://dx.doi.org/10.1158/1055-9965.EPI-14-1314

16. Kanerva N, Rissanen H, Knekt P, Havulinna A, Eriksson J, Männistö S. The healthy Nordic diet and incidence of type 2 diabetes-10-years follow up. Diabetes Res Clin Pract 2014; 106: e34-7.

17. Kanerva N, Kaartinen NE, Rissanen H, Knekt P, Eriksson JG, Sääksjärvi K, et al. Associations of the Baltic Sea diet with cardiometabolic risk factors - a meta-analysis of three Finnish studies. Br J Nutr 2014; 112: 616-26.

18. Roswall N, Eriksson U, Sandin S, Löf M, Olsen A, Skeie G, et al. Adherence to the healthy Nordic food index, dietary composition, and lifestyle among Swedish women. Food Nutr Res 2015; 59: 26336, doi: http://dx.doi.org/10.3402/fnr.v59.26336

19. ISRCTN Registry. Available from: http://www.isrctn.com/ search?q=\%C3\%98verby [cited 24 April 2015].

20. Bere E, Brug J. Towards health-promoting and environmentally friendly regional diets-a Nordic example. Public Health Nutr 2009; 12: 91-6.

21. Mithril C, Dragsted LO, Meyer C, Blauert E, Holt MK, Astrup A. Guidelines for the New Nordic Diet. Public Health Nutr 2012; 1: 1-7.

22. Mithril C, Dragsted LO, Meyer C, Tetens I, Biltoft-Jensen A, Astrup A. Dietary composition and nutrient content of the New Nordic Diet. Public Health Nutr 2013; 16: 777-85.

23. Bjørnarå HB, Hillesund ER, Torstveit MK, Stea TH, Øverby NC, Bere E. An assessment of the test-retest reliability of the New Nordic Diet score. Food Nutr Res 2015; 59: 28397, doi: http://dx.doi.org/10.3402/fnr.v59.28397

24. Melnæs BK, Lundberg-Hallén N, Helland-Kigen KM, LundBlix NA, Myhre JB, Johansen AMW, et al. 'Norkost 3', a national dietary survey conducted among Norwegian men and women aged 18-70 years, 2010-11. Oslo: The Norwegian Directorate of Health Affairs; 2012.

25. The Norwegian food composition table. 2006. Available from: http://www.matportalen.no/verktoy/the_norwegian_food_ composition_table/old_tables [cited 17 April 2015].

26. Helsedirektoratet (2014). Anbefalinger om kosthold, ernæring og fysisk aktivitet. Oslo: Helsedirektoratet. Contract No: IS-2170.

27. The Norwegian Health Directorate: Nutrition Recommendations to Promote Public Health and Prevent Chronic Diseases (2011). Methodology and scientific knowledge base. Oslo: Norwegian Ministries. Contract No: IS-1881.

28. St-Onge M, Mignault D, Allison DB, Rabasa-Lhoret R. Evaluation of a portable device to measure daily energy expenditure in free-living adults. Am J Clin Nutr 2007; 85: 742-9.

29. Ward DS, Evenson KR, Vaughn A, Rodgers AB, Troiano RP. Accelerometer use in physical activity: best practices and research recommendations. Med Sci Sports Exerc 2005; 37(11 Suppl): $582-8$.

30. Scheers T, Philippaerts R, Lefevre J. Variability in physical activity patterns as measured by the SenseWear Armband: how many days are needed? Eur J Appl Physiol 2012; 112: 1653-62.

31. World Health Organization. Global recommendations on physical activity for health. 2010. Available from: http://apps. who.int/iris/handle/10665/44399 [cited 13 November 2015].

32. Garber CE, Blissmer B, Deschenes MR, Franklin BA, Lamonte MJ, Lee IM, et al. American College of Sports Medicine Position Stand. Quantity and quality of exercise for developing and maintaining cardiorespiratory, musculoskeletal, and neuromotor fitness in apparently healthy adults: guidance for prescribing exercise. Med Sci Sports Exerc 2011; 43: 1334-59. 
33. World Health Organization. Obesity and overweight. Fact sheet No. 311 [Updated January 2015]. 2011. Available from: http:// www.who.int/mediacentre/factsheets/fs311/en/ [cited 18 November 2015].

34. World Cancer Research Fund | American Institute for Cancer Research (2007). Food, nutrition, physical activity, and the prevention of cancer: a global perspective. Washington, DC: American Institute for Cancer Research; 2007.

35. Podsakoff PM, MacKenzie SB, Lee J-Y, Podsakoff NP. Common method biases in behavioral research: a critical review of the literature and recommended remedies. J Appl Psychol 2003; 88: 879-903.

36. Willett W. Nutritional epidemiology. 3rd ed. New York: Oxford University Press; 2013.

37. Livingstone MBE, Black AE. Markers of the validity of reported energy intake. J Nutr 2003; 133: 895S-920S.

38. McCambridge J, Witton J, Elbourne DR. Systematic review of the Hawthorne effect: new concepts are needed to study research participation effects. J Clin Epidemiol 2014; 67: 26777.

39. Helsedirektoratet (2015). Fysisk aktivitet og sedat tid blant voksne og eldre i Norge. Nasjonal kartlegging 2014-2015. Oslo: Helsedirektoratet.
40. Moeller SM, Reedy J, Millen AE, Dixon LB, Newby P, Tucker $\mathrm{KL}$, et al. Dietary patterns: challenges and opportunities in dietary patterns research: an experimental biology workshop, April 1, 2006. J Am Diet Assoc 2007; 107: 1233-9.

41. Waijers PM, Feskens EJ, Ocké MC. A critical review of predefined diet quality scores. Br J Nutr 2007; 97: 219-31.

42. Bach A, Serra-Majem L, Carrasco JL, Roman B, Ngo J, Bertomeu I, et al. The use of indexes evaluating the adherence to the Mediterranean diet in epidemiological studies: a review. Public Health Nutr 2006; 9: 132-46.

43. Brussaard J, Löwik M, Steingrimsdottir L, Møller A, Kearney J, De Henauw S, et al. A European food consumption survey method - conclusions and recommendations. Eur J Clin Nutr 2002; 56(Suppl 2): S89-94.

\footnotetext{
*Helga Birgit Bjørnarå

Department of Public Health

Sport and Nutrition, Faculty of Health and Sport Sciences

University of Agder

Post Box 422, NO-4604 Kristiansand

Norway

Email: helga.birgit.bjornara@uia.no
} 
Appendix 1. The components underlying the construction of the 10 subscales within the NND score $(n=75)$

\begin{tabular}{|c|c|c|c|c|c|}
\hline Subscale & Related question(s) & $\begin{array}{l}\text { Response alternatives } \\
\text { and coding }\end{array}$ & Calculations (min-max) & Median $=$ cut-off & $\begin{array}{l}\text { Dietary behavior } \\
\text { associated with } \\
\text { scoring }\end{array}$ \\
\hline Meal pattern & $\begin{array}{l}\text { How often do you eat } \\
\text {-Breakfast } \\
\text {-Lunch } \\
\text {-Dinner } \\
\text {-Evening } \\
\text { meal/supper }\end{array}$ & $\begin{array}{l}\text { Never }=0 \\
\text { Less than once a week }=0.5 \\
\text { Once a week }=1 \\
\text { Twice a week }=2 \\
\text { Three times a week }=3 \\
\text { Four times a week }=4 \\
\text { Five times a week }=5 \\
\text { Six times a week }=6 \\
\text { Every day }=7\end{array}$ & $\begin{array}{l}\text { Sum of answers to the four questions } \\
(0-28)\end{array}$ & $\begin{array}{l}\text { Women: } 25.0 \\
\text { Men: } 25.0\end{array}$ & $\begin{array}{l}\text { Women: } \\
<25.0=0 \\
\geq 25.0=1 \\
\text { Men: } \\
\leq 25.0=0 \\
>25.0=1\end{array}$ \\
\hline Nordic fruits & $\begin{array}{l}\text { How often do you eat } \\
\text { typical Nordic fruits } \\
\text { (apple, pear, plum) }\end{array}$ & $\begin{array}{l}\text { Never }=0 \\
\text { Less than once a week }=0.5 \\
\text { Once a week }=1 \\
\text { Twice a week }=2 \\
\text { Three times a week }=3 \\
\text { Four times a week }=4 \\
\text { Five times a week }=5 \\
\text { Six times a week }=6 \\
\text { Every day }=7 \\
\text { Several times a day }=10\end{array}$ & $\begin{array}{l}\text { No calculation } \\
(0-10)\end{array}$ & $\begin{array}{l}\text { Women: } 4.0 \\
\text { Men: } 3.5\end{array}$ & $\begin{array}{l}\text { Women: } \\
\leq 4.0=0 \\
>4.0=1 \\
\text { Men: } \\
\leq 3.5=0 \\
>3.5=1\end{array}$ \\
\hline $\begin{array}{l}\text { Root } \\
\text { vegetables }\end{array}$ & $\begin{array}{l}\text { How often do you eat } \\
\text { root vegetables (e.g. } \\
\text { carrot, rutabaga, } \\
\text { onion)? }\end{array}$ & $\begin{array}{l}\text { Never }=0 \\
\text { up to } \\
\text { Several times a day }=10\end{array}$ & $\begin{array}{l}\text { No calculation } \\
(0-10)\end{array}$ & $\begin{array}{l}\text { Women: } 5.0 \\
\text { Men: } 4.5\end{array}$ & $\begin{array}{l}\text { Women: } \\
\begin{array}{l}\leq 5.0=0 \\
>5.0=1 \\
\text { Men: } \\
\leq 4.5=0 \\
>4.5=1\end{array}\end{array}$ \\
\hline Cabbages & $\begin{array}{l}\text { How often do you eat } \\
\text { cabbages (e.g. } \\
\text { cauliflower, broccoli, } \\
\text { Brussels sprouts, } \\
\text { kale)? }\end{array}$ & $\begin{array}{l}\text { Never }=0 \\
\text { up to } \\
\text { Several times a day }=10\end{array}$ & $\begin{array}{l}\text { No calculation } \\
(0-10)\end{array}$ & $\begin{array}{l}\text { Women: } 3.0 \\
\text { Men: } 3.0\end{array}$ & $\begin{array}{l}\text { Women: } \\
\leq 3.0=0 \\
>3.0=1 \\
\text { Men: } \\
<3.0=0 \\
\geq 3.0=1\end{array}$ \\
\hline $\begin{array}{l}\text { Potatoes vs. } \\
\text { rice/pasta }\end{array}$ & $\begin{array}{l}\text { How often do you eat } \\
\text {-Potatoes } \\
\text {-Rice } \\
\text {-Pasta }\end{array}$ & $\begin{array}{l}\text { Never }=0 \\
\text { up to } \\
\text { Several times a day }=10\end{array}$ & $\begin{array}{l}\text { Frequency of eating potatoes relative } \\
\text { to eating rice and pasta combined: } \\
\text { potatoes } /(0.1+\text { rice }+ \text { pasta }) \\
(0-100)\end{array}$ & $\begin{array}{l}\text { Women: } 0.49 \\
\text { Men: } 0.39\end{array}$ & $\begin{array}{l}\text { Women: } \\
\leq 0.49=0 \\
>0.49=1 \\
\text { Men: } \\
<0.39=0 \\
\geq 0.39=1\end{array}$ \\
\hline $\begin{array}{l}\text { Whole grain } \\
\text { breads vs. } \\
\text { white } \\
\text { breads }\end{array}$ & $\begin{array}{l}\text { How often do you eat } \\
\text {-Refined breads/bread } \\
\text { rolls } \\
\text {-Whole grain breads } \\
\text {-Whole grain hard } \\
\text { breads }\end{array}$ & $\begin{array}{l}\text { Never }=0 \\
\text { up to } \\
\text { Several times a day }=10\end{array}$ & $\begin{array}{l}\text { Frequency of eating whole grain } \\
\text { breads and whole grain hard breads } \\
\text { combined relative to eating refined } \\
\text { breads: } \\
\text { (whole grain breads + whole grain } \\
\text { hard breads }) /(0.1+\text { refined breads) } \\
(0-200)\end{array}$ & $\begin{array}{l}\text { Women: } 15.0 \\
\text { Men: } 9.6\end{array}$ & $\begin{array}{l}\text { Women: } \\
\begin{array}{c}\leq 15.0=0 \\
>15.0=1 \\
\text { Men: } \\
\leq 9.6=0 \\
>9.6=1\end{array}\end{array}$ \\
\hline
\end{tabular}




\begin{tabular}{|c|c|c|c|c|c|}
\hline Subscale & Related question(s) & $\begin{array}{l}\text { Response alternatives } \\
\text { and coding }\end{array}$ & Calculations (min-max) & Median $=$ cut-off & $\begin{array}{c}\text { Dietary behavior } \\
\text { associated with } \\
\text { scoring }\end{array}$ \\
\hline Oatmeal & $\begin{array}{l}\text { How often do you eat } \\
\text { oatmeal? }\end{array}$ & $\begin{array}{l}\text { Never }=0 \\
\text { up to } \\
\text { Several times a day }=10\end{array}$ & $\begin{array}{l}\text { No calculation } \\
(0-10)\end{array}$ & $\begin{array}{l}\text { Women: } 1.0 \\
\text { Men: } 0.75\end{array}$ & 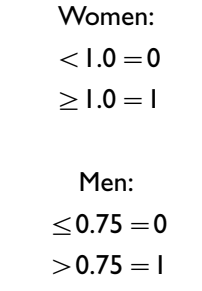 \\
\hline $\begin{array}{l}\text { Foods from } \\
\text { the wild } \\
\text { countryside }\end{array}$ & $\begin{array}{l}\text { How often do you eat } \\
\text {-Game (e.g. moose, } \\
\text { reindeer, deer) } \\
\text {-Lean fish (e.g. cod, } \\
\text { Pollock, haddock) } \\
\text {-Fatty fish (e.g. } \\
\text { mackerel, herring, } \\
\text { halibut) } \\
\text {-Other seafood (e.g. } \\
\text { shrimps, crabs, } \\
\text { mussels } \\
\text {-Berries }\end{array}$ & $\begin{array}{l}\text { Never }=0 \\
\text { up to } \\
\text { Several times a day }=10\end{array}$ & $\begin{array}{l}\text { Sum of answers to the five } \\
\text { questions } \\
(0-50)\end{array}$ & Men: 4.5 & $\begin{array}{l}\text { Women: } \\
<4.5=0 \\
\geq 4.5=1 \\
\text { Men: } \\
\leq 4.5=0 \\
>4.5=1\end{array}$ \\
\hline Milk vs. juice & $\begin{array}{l}\text { How often do you } \\
\text { drink } \\
\text {-Milk } \\
\text {-Fruit juice without } \\
\text { added sugar }\end{array}$ & $\begin{array}{l}\text { Never }=0 \\
\text { up to } \\
\text { Several times a day }=10\end{array}$ & $\begin{array}{l}\text { Frequency of drinking milk relative } \\
\text { to drinking fruit juice: } \\
\text { milk/(0.I + juice }) \\
(0-100)\end{array}$ & $\begin{array}{l}\text { Women: } 1.29 \\
\text { Men: } 2.5\end{array}$ & $\begin{array}{c}\text { Women: } \\
\leq 1.29=0 \\
>1.29=1 \\
\text { Men: } \\
\leq 2.5=0 \\
>2.5=1\end{array}$ \\
\hline $\begin{array}{l}\text { Water vs. } \\
\text { sugar/ } \\
\text { artificially } \\
\text { sweetened } \\
\text { beverages }\end{array}$ & $\begin{array}{l}\text { How often do you } \\
\text { drink } \\
\text {-Water } \\
\text {-Sugar-sweetened } \\
\text { beverages } \\
\text {-Artificially sweetened } \\
\text { beverages }\end{array}$ & $\begin{array}{l}\text { Never }=0 \\
\text { up to } \\
\text { Several times a day }=10\end{array}$ & $\begin{array}{l}\text { Frequency of drinking water relative } \\
\text { to drinking sugar-sweetened } \\
\text { beverages and artificially sweetened } \\
\text { beverages combined: } \\
\text { water/( } 0.1 \text { + sugar-sweetened } \\
\text { beverages + artificially sweetened } \\
\text { beverages) } \\
(0-100)\end{array}$ & $\begin{array}{l}\text { Women: } 6.25 \\
\text { Men: } 2.8\end{array}$ & $\begin{array}{l}\text { Women: } \\
\begin{array}{c}\leq 6.25=0 \\
>6.25=1 \\
\text { Men: } \\
\leq 2.8=0 \\
>2.8=1\end{array}\end{array}$ \\
\hline
\end{tabular}

NND, New Nordic Diet. 